\title{
Smartphone Usage: Reasons among Gender in University of Cyberjaya, Selangor, Malaysia
}

\author{
Muhammad Luqmanul Hakim Abd Latif ${ }^{1}$, Izzah Zarifah Ibrahim², \\ Nur Amalia Saiful Nizam³, Nik Balqis Athirah Abdul Aziz ${ }^{4}$, \\ Sabariah Abd Hamid ${ }^{5}$
}

${ }^{1-5}$ Faculty of Medicine, University of Cyberjaya, Malaysia

Corresponding Author: Sabariah Abd Hamid

\begin{abstract}
Smartphones have been an essential device in most of our daily activities. However, there is not much information regarding the difference of smartphone usage between gender among medical students. Therefore, this study aims to determine the prevalence of smartphone usage and the reasons of its usage among medical students by gender.

A cross-sectional study was done, using selfadministered questionnaires given to 300 medical students in University of Cyberjaya. The students were selected using stratified and simple random sampling methods.

All respondents were using smartphone with majority from age of 18-21 years old (55.3\%), female (67.7\%), Malay (85\%) and studying in 1st year $(24.7 \%)$. The most popular reason of smartphone usage for male and female was entertainment mainly leisure activity (91.8\% and $93.6 \%$, respectively).

There was no significant difference between gender and reasons of smartphone usage among medical students. Regardless, time must be managed wisely to avoid overuse of smartphones that can disrupt relationships with others.
\end{abstract}

Keywords: smartphone, reason, medical student, gender, Selangor

\section{INTRODUCTION}

Smartphone is defined as "a computing device with a screen, one that is small enough to be held in one hand, that supports cellular, Wi-Fi connectivity and telephone calling that has the ability to download, install and run applications. [1] A study on the prevalence of smartphone usage among International Islamic University Students reveals, out of 40 respondents, $90 \%$ owned and used a smartphone. ${ }^{[2]}$ This finding is consistent with a research among 460 medical students in Jeddah University that shows high level of smartphone use and ownership (99.4\%) among students. ${ }^{[3]}$

Another study showed that among 1441 smartphone users, shows that $51.7 \%$ were female. ${ }^{[4]}$ Next, a study done in United States stated that $93.7 \%$ of smartphone apps consumer report having apps, 69.2\% having used health apps, and $55.7 \%$ having used brain training apps. Among the consumers, $66.9 \%$ reported that brain training apps helped with thinking, 69.3\% with attention, 53.3\% with mood, $65 \%$ with memory. ${ }^{[5]}$ A study among 30 medical students in India showed most of the students used smartphone two hours daily (80\%) for texting/browsing/social media (83\%). [6] Lastly, Majority of the Malaysian respondents were using mobile phone for communication purposes (87.8\%), photo shooting (59.7\%), entertainment (58.2\%), and educational/academic purposes $(43.8 \%){ }^{\text {[7] }}$

Therefore, this study aims to identify the prevalence of smartphone usage and the reasons among medical students in University of Cyberjaya by gender. 


\section{MATERIALS AND METHODS}

A cross-sectional study was done in University of Cyberjaya (UOC) as there has not been a recent study done in the university regarding reasons of smartphone usage among gender. Three hundred students were chosen among 550 medical students ranging from Year 1 to Year 5 based on stratified and convenience sampling. Inclusion criteria was Malaysian and those who were absent or refuse to participate on the day of data collection were count as non-response.

The respondents who agreed to sign the consent were given the questionnaires according to their timetable and the questionnaires will be collected at the end of the day by the researchers. The questionnaires that was used in this study were adopted and revised from The Generalised Anxiety Disorder-2 (GAD2) and Smartphone Addiction Scale: Short Version (SAS-SV) questionnaires. ${ }^{[8]}$ Data collected were recorded and analyzed using Statistical Package for the Social Sciences (SPSS).

The association between gender and reason of smartphone usage was determined

Table 2: The reasons of smartphone usage by gender prevalence of smartphone usage

\begin{tabular}{|l|l|l|l|l|}
\hline \multirow{2}{*}{ Reasons } & \multicolumn{2}{|l|}{ Male (N=97) } & \multicolumn{2}{l|}{ Female (N=203) } \\
\cline { 2 - 5 } & $\begin{array}{l}\text { Yes } \\
\boldsymbol{n}(\%)\end{array}$ & $\begin{array}{l}\text { No } \\
\boldsymbol{n}(\%)\end{array}$ & $\begin{array}{l}\text { Yes } \\
\boldsymbol{n}(\%)\end{array}$ & $\begin{array}{l}\text { No } \\
\boldsymbol{n}(\%)\end{array}$ \\
\hline Leisure activity & 89 & 8 & 190 & 13 \\
& $(91.8)$ & $(8.2)$ & $(93.6)$ & $(6.4)$ \\
\hline Study related & 82 & 15 & 181 & 22 \\
& $(84.5)$ & $(15.5)$ & $(89.2)$ & $(10.8)$ \\
\hline Texting & 80 & 17 & 175 & 28 \\
& $(82.5)$ & $(17.5)$ & $(86.2)$ & $(13.8)$ \\
\hline Social media & 76 & 21 & 187 & 16 \\
& $(78.4)$ & $(21.6)$ & $(92.1)$ & $(7.9)$ \\
\hline Calling & 66 & 31 & 150 & 53 \\
members & $(68.0)$ & $(32.0)$ & $(73.9)$ & $(26.1)$ \\
\hline Mobile gaming & 63 & 34 & 82 & 121 \\
& $(64.9)$ & $(35.1)$ & $(40.4)$ & $(59.6)$ \\
\hline Calling friends & 57 & 40 & 122 & 81 \\
& $(58.8)$ & $(41.2)$ & $(60.1)$ & $(39.9)$ \\
\hline Reading news & 57 & 40 & 114 & 89 \\
& $(58.8)$ & $(41.2)$ & $(56.2)$ & $(43.8)$ \\
\hline Online usage & 5 & 92 & 6 & 197 \\
& $(5.2)$ & $(94.8)$ & $(3.0)$ & $(97.0)$ \\
\hline \multicolumn{2}{|l|}{$P>0.05$} & & \\
\hline
\end{tabular}

Table 2 shows the most popular reason for smartphone usage among males and females is leisure activity (91.8\% and $93.6 \%$ respectively). by Pearson chi-square test. The level of significance was set at $p<0.05$ and confidence level at 95\%.

\section{RESULT}

The total number of respondents was 300 with $100 \%$ response rate.

Table 1: The prevalence of smartphone usage among respondents by socio demographic characteristic

\begin{tabular}{|l|l|l|l|}
\hline Socio-demography & Frequency & Percentage & p-value \\
\hline Age (years) & & & \\
\hline $18-21$ & 166 & 55.3 & \\
\hline $22-25$ & 133 & 41.7 & $<0.001$ \\
\hline $26-29$ & 1 & 3.0 & \\
\hline Gender & & & \\
\hline Male & 97 & 32.3 & $<0.001$ \\
\hline Female & 203 & 67.7 & \\
\hline Ethnicity & 255 & & \\
\hline Malay & 12 & 85.0 & \\
\hline Chinese & 29 & 4.0 & $<0.001$ \\
\hline Indian & 4 & 9.7 & \\
\hline Others & & 1.3 & \\
\hline Year of study & 74 & 24.7 & \\
\hline Year 1 & 54 & 18.0 & \\
\hline Year 2 & 57 & 19.0 & 0.264 \\
\hline Year 3 & 52 & 17.3 & \\
\hline Year 4 & 63 & 21.0 & \\
\hline Year 5 & 300 & 100 & \\
\hline TOTAL & & \\
\hline
\end{tabular}

Majority of the respondents were students with age of 18-21 years old (55.3\%), female (67.7\%), Malay (85\%) and studying in 1st year (24.7\%) (Table I).

Top reasons of smartphone usage for males is leisure activity (91.8\%), followed by study related (84.5\%) and texting (82.5\%), while leisure activity (93.6\%), social media (92.1\%) and study related (89.2\%) are popular reasons among female.

It is also highly indicative that there is no significant association between gender and reason of smartphone usage ( $p>0.05)$.

\section{DISCUSSION}

Majority (55.3\%) of the respondents who use smartphones are in the age group of 18-21 years old. This is similar to a study done in Brazil, which states that $85 \%$ of those ages 18 to 34 own a smartphone compared with just $32 \%$ of those 50 and older. Even in countries like Germany and Australia, where smartphone ownership rates far outpace those in Brazil, younger adults are far more likely to own smartphones than older age groups. ${ }^{[9]}$ This 
may due to high dependency on hand phone was observed among respondents, in particular the youngsters. For instance, more than $80 \%$ of them feel anxious and would go back if they had left their phone, waking up in the middle of the night to check their phone and could not last an hour to check their phone after waking up. ${ }^{[10]}$

In our study, female has the higher prevalence in smartphone usage compared to male with the percentage of $67.6 \%$. This is different from a study done in Malaysia that showed the male users have continued to outnumber female users, where males made up 58.9\% while females account for $41.1 \%$, a ratio of $1.43 .{ }^{[10]}$ This was also supported by a study conducted in Saudi Arabia which stated that male consumers tend to have higher familiarity towards smartphone compared to their female counterparts. ${ }^{[11]}$ The difference might be due to female have more natural desire to connect with friends and family, as a method for sharing information and catching up. [12]

This is supported by a study done among 324 university students in Najran, Saudi Arabia, ${ }^{[11]}$ which found that making a phone call (83.2\%), browsing Internet (79.9\%), downloading software (74.9\%) and sending text messages (65.0\%) are among the top types of usage. In comparison with our study, $72.0 \%$ of the users use smartphones to call family members. This similarity might be due to the same age group of university students, where in the Najran study, $97.5 \%$ of the respondents are from the 19-30 years old age group, compared to our study, where $100 \%$ of the respondents are from the 18-29 years old age group.

A national survey done in Malaysia by Malaysian Communications and Multimedia Commission (MCMC) found that $88.6 \%$ of the users use smartphones for social media and $56.4 \%$ use them to play games, ${ }^{[13]}$ which was similar with our result where $87.7 \%$ of our respondents use phones for social media and $48.3 \%$ of them use for mobile gaming. This could be explained by high ownership of smartphones among the younger age groups, where in the MSMC study, $87.0 \%$ of the 20 -34 years old age group own smartphones.

Majority of our respondents use the smartphone as a source of entertainment. While male use their smartphone to play mobile games, female tend to use for social networks such as Instagram and Facebook. This is similar to another study done among medical students in China, which stated that male students were more likely to play games, watch mobile phone videos, and listen to music, whereas female students were more inclined to use the social networking services and mobile phone communication functions. ${ }^{[4]}$ A study done among 266 students in Korea also found that $55.4 \%$ of males and $44.6 \%$ of females use their phones to access social media [14] compared to $78.4 \%$ of males and $92.1 \%$ of females in our study. This large difference could be due to social media applications such as Facebook, Twitter, Instagram, Snapchat which have become widely popular in recent years, hence attracting the younger generations, including university students. A local study found that $95.3 \%$ of university students subscribed to Facebook. [15]

A study in China has reported a significant different in usage of smartphone between gender where smartphone games among male $(\mathrm{aOR}=2.27$; 95\% CI: $1.17-$ 4.42) and multimedia applications among female $(\mathrm{aOR}=2.22 ; 95 \% \mathrm{CI}: 1.37-3.59)$. [4] However, our study showed no significant difference between gender and reason of smartphone usage $(p>0.05)$.

Limitations for this study include small sample size, where ideally, the study should be done nationwide among various medical schools. Small sample size might lead to large standard error and result in wide range of confidence interval.

\section{CONCLUSION}

Almost all respondents are using smartphone and majority are using smartphone for entertainment. However, 
this study identified no significant difference between reason of smartphone usage and gender.

Although smartphone can prove to be an advantageous learning and communicating tool, university students must have good conscience on how to benefit optimally from using them as increase in smartphone usage could be a factor that influence causal pathway leading to mental health problem such as anxiety, depression and poor sleep quality

Therefore, university should create a health education programs and intervention to counter with increase in smartphone usage among university student and provide counseling service to students that are already addicted to their smartphone. The students should also be monitored closely for their result. It is also recommended that the university conduct mental health status examination in order to improve their student's mental well-being.

\section{ACKNOWLEDGEMENT}

The authors would like to acknowledge the University of Cyberjaya (UoC) for giving the permission to carry out this study. This work was fully guided and supported by our supervisor, Dr Sabariah Abd Hamid, Public Health Coordinator in UoC and Madam Norhafizah Abd Manan, Research and Evidence-Based Medicine Coordinator, UoC.

We would also like to show our appreciation to our seniors Fatin Izlaili Zaini, Mariyam Nadha Ibrahim Zameer, Muhammad Nurazwan bin Rahim and Nur Izzati binti Abdul Rahman for their effort in writing the proposal for this research.

Lastly, we would like to thank all the respondents for their time and cooperation.

Conflict of Interest: None

Source of Funding: None

Ethical Approval: Approved

\section{REFERENCES}

1. Jubien P. Shape shifting smartphones: Riding the waves in post-secondary education. Canadian Journal of Learning and Technology (CJLT). 2013; 39(2):1-16.

2. Qadri M, Abubaka Y, Ibrahim J. Prevalence of mobile usage among university students: A case study of International Islamic University Malaysia. International Journal of Scientific and Research Publications (IJSRP). 2015;5(12)655-659.

3. Zaid S, Abdulaziz A, Osama A, Mariam B, Tahir J, Mukhtiar B. Utilization of smartphones related medical applications among medical students at King Abdulaziz University, Jeddah: A cross-sectional study. Journal of Infection and Public Health (JIPH). 2016;9(6):691-697.

4. Chen B, Liu F, Ding S, Ying X, Wang L, Wen Y. Gender differences in factors associated with smartphone addiction: a cross-sectional study among medical college students. BioMed Central (BMC) Psychiatry. 2017;17(341):1-9.

5. Torous J, Staples J, Fenstermacher E, Dean J, Keshavan M. Barriers, Benefits, and Beliefs of Brain Training Smartphone Apps: An Internet Survey of Younger US Consumers. Frontiers in Human Neuroscience. 2016;10(180):1-8.

6. Aswitha PS, Rajajeyakumar M, Anushuya M, Hariesh N, Krithikka R, Taherakumar, et al. Prevalence of Smartphone Users at Risk for Developing Cell Phone Vision Syndrome among College Students. Journal of Psychology and Psychotherapy (JPP). 2017;7(3): 1-3.

7. Subramani P, Aaseer TS, Stephanie WKY, Bobie LCC, Lee YR. Smartphone usage and increased risk of mobile phone addiction: A concurrent study. International Journal of Pharmaceutical Investigation. 2017;7(3)125-131.

8. Boumosleh, J.M. and Jaalouk, D. Depression, anxiety, and smartphone addiction in university students- A cross sectional study. PLoS ONE. 2017;12(8).

9. Malaysian Communications and Multimedia Commision. Hand Phone Users Survey 2017 [Internet]. Malaysian Communications and Multimedia Commission; 2017.

10. Mohd AO, Abdullah ZT, Zainal AS, Tan SY, Abdullah SA. A Study of the Trend of Smartphone and its Usage Behavior in Malaysia. International Journal on New 
Muhammad Luqmanul Hakim Abd Latif et.al. Smartphone usage: reasons among gender in University of Cyberjaya, Selangor, Malaysia.

Computer Architectures and Their Applications (IJNCAA). 2012;2(1):274-285.

11. Hejab MA, Shaidah J. Smartphones usage among university students: Najran University case. International Journal of Academic Research (IJAR) Part B. 2014; 6(2):321-326.

12. United Kingdom Online Measurement Insights. Smartphones - How women are driving time online [Internet]. United Kingdom Online Measurement; 2016.

13. Malaysian Communications and Multimedia Commission (MCMC). Hand Phone Users Survey 2018 [Internet]. Malaysian Communications and Multimedia Commission; 2018.

14. Park N, Lee H. Gender difference in social networking on smartphones: A case study of
Korean college student smartphone users. International Telecommunications Policy Review. 2014;21(2):1-18.

15. Saodah W, Syed AI, Norealyna M. Social media use for information-sharing activities among youth in Malaysia. Journalism and Mass Communication. 2012;2(11):10291047.

How to cite this article: Muhammad Luqmanul Hakim Abd Latif, Izzah Zarifah Ibrahim, Nur Amalia Saiful Nizam et.al. Smartphone usage: reasons among gender in University of Cyberjaya, Selangor, Malaysia. International Journal of Science \& Healthcare Research. 2021; 6(4): 361-365. DOI: https://doi.org/10. 52403/ijshr.20211050 